\title{
Comparative expression profiling in grape (Vitis vinifera) berries derived from frequency analysis of ESTs and MPSS signatures Alberto Iandolino ${ }^{1,3}$, Kan Nobuta ${ }^{2}$, Francisco Goes da Silva1, Douglas R Cook ${ }^{1}$ and Blake C Meyers*2
}

Address: ${ }^{1}$ Department of Plant Pathology and College of Agricultural and Environmental Sciences Genomics Facility, University of California, One Shields Avenue, Davis, CA 95616, USA, 2Department of Plant and Soil Sciences \& Delaware Biotechnology Institute, University of Delaware, Newark, Delaware 19711, USA and ${ }^{3}$ Monsanto, 1920 5th Street, Davis, 95616, California, USA

Email: Alberto Iandolino - abi.hss@gmail.com; Kan Nobuta - nobuta@dbi.udel.edu; Francisco Goes da Silva - fdgoesdasilva@ucdavis.edu; Douglas R Cook -drcook@ucdavis.edu; Blake C Meyers* - meyers@dbi.udel.edu

* Corresponding author

Published: 12 May 2008

BMC Plant Biology 2008, 8:53 doi:10.1 I86/147|-2229-8-53
Received: 26 June 2007

Accepted: 12 May 2008

This article is available from: http://www.biomedcentral.com/I47I-2229/8/53

(c) 2008 landolino et al; licensee BioMed Central Ltd.

This is an Open Access article distributed under the terms of the Creative Commons Attribution License (http://creativecommons.org/licenses/by/2.0), which permits unrestricted use, distribution, and reproduction in any medium, provided the original work is properly cited.

\begin{abstract}
Background: Vitis vinifera $(V$. vinifera) is the primary grape species cultivated for wine production, with an industry valued annually in the billions of dollars worldwide. In order to sustain and increase grape production, it is necessary to understand the genetic makeup of grape species. Here we performed mRNA profiling using Massively Parallel Signature Sequencing (MPSS) and combined it with available Expressed Sequence Tag (EST) data. These tag-based technologies, which do not require a priori knowledge of genomic sequence, are well-suited for transcriptional profiling. The sequence depth of MPSS allowed us to capture and quantify almost all the transcripts at a specific stage in the development of the grape berry.

Results: The number and relative abundance of transcripts from stage II grape berries was defined using Massively Parallel Signature Sequencing (MPSS). A total of 2,635,293 17-base and 2,259,286 20-base signatures were obtained, representing at least 30,737 and 26,878 distinct sequences. The average normalized abundance per signature was $\sim 49$ TPM (Transcripts Per Million). Comparisons of the MPSS signatures with available Vitis species' ESTs and a unigene set demonstrated that 6,430 distinct contigs and 2,190 singletons have a perfect match to at least one MPSS signature. Among the matched sequences, ESTs were identified from tissues other than berries or from berries at different developmental stages. Additional MPSS signatures not matching to known grape ESTs can extend our knowledge of the V. vinifera transcriptome, particularly when these data are used to assist in annotation of whole genome sequences from Vitis vinifera.

Conclusion: The MPSS data presented here not only achieved a higher level of saturation than previous EST based analyses, but in doing so, expand the known set of transcripts of grape berries during the unique stage in development that immediately precedes the onset of ripening. The MPSS dataset also revealed evidence of antisense expression not previously reported in grapes but comparable to that reported in other plant species. Finally, we developed a novel web-based, public resource for utilization of the grape MPSS data [I].
\end{abstract}




\section{Background}

Grapes species (Vitis spp.) represent the most widely cultivated and economically important fruit crop in the world [2]. The use of grape berries includes the production of juice, fresh and dried fruit, and distilled liquor, although wine produced from cultivars of $V$. vinifera has the highest economic value of grape products. Grapevine berries are non-climacteric fruits with a characteristic double sigmoid growth curve. The initial phase of exponential berry growth (stage I) is followed by a lag phase (stage II), with growth resuming after the onset of ripening or "veraison" (stage III). Berry development is characterized by changes in numerous biological processes, including cell division and enlargement, primary and secondary metabolism, and resistance or susceptibility to abiotic or biotic stresses $[3,4]$. The importance of this plant species to agriculture has made the development of genomic resources a high priority. Among these resources, transcriptional profiling of important grape tissues is a practical option that may reveal transcriptional complexity and changes in this dynamic developmental system.

Massively parallel signature sequencing technology (MPSS) $[5,6]$ is a sequence-based method for measuring gene expression. The depth of sampling provided by MPSS can identify a nearly complete inventory of transcripts in a given sample. The method is based on a unique process for parallel sequencing, which starts with the cloning of a cDNA library on $5 \mu \mathrm{m}$ diameter microbeads; one transcript from the original RNA sample is represented on a single bead [5]. From each bead, a sequence of the 'signature' of 17 or more nucleotides is obtained by successive round of sequencing reactions [57]. These signatures are derived from and include the most 3 ' occurrence of a specific restriction enzyme site in a transcript (most often DpnII, producing signatures that start with GATC) $[5,6]$. The output of the method is conceptually similar to a possibly more familiar method called Serial Analysis of Gene Expression (SAGE) [8]. However, the MPSS technology permits the simultaneous sequencing of millions of signatures from a given library [5]. By matching these signatures to the genome to identify specific genes, the abundance of each signature represents and measures the gene expression levels in the sample tissue. Among several published applications of this technology, we have previously conducted comprehensive transcriptional analyses of the reference plant species Arabidopsis thaliana and rice $[7,9]$. While MPSS, SAGE, and expressed sequence tags (ESTs) are all sequence-based technologies for transcriptional profiling, MPSS provides more thorough qualitative and quantitative description of gene expression due to its tremendous depth. While novel sequencing technologies, such as sequence-by-synthesis (SBS) and 454, offer deeper sequencing and longer read lengths, none have yet demonstrated consistently better results than MPSS for mRNA profiling [10].

In this report, we have measured gene expression in developing grape berries using MPSS, compared this expression profile with that provided by the current Vitis Unigene set [4], and we developed a novel web-based resource for utilization of the grape MPSS data. As a result of this analysis, we were able to annotate thousands of signatures matching predicted genes, quantify the expression level of these genes in the developing berries, compare the expression profiles derived from ESTs and MPSS signature frequencies, and expand the coverage of known transcripts in an important grapevine organ at a specific developmental stage. Because these data are based on sequences, they comprise a resource that will be useful for the annotation of any grape genomic sequence produced in the future.

\section{Results \\ Analysis of the V. vinifera berry MPSS dataset and signature annotation}

An MPSS library was constructed using RNA extracted from stage II berries (green, hard) that were sampled from field-grown V. vinifera cv. Cabernet Sauvignon. After cloning of the cDNA library onto beads, 17-base and 20-base signatures were generated by MPSS sequencing [5,6]. We note that these are not independent samples, in that 20base signatures are obtained by extending previously recorded 17-base signatures by three nucleotides; due to a low failure rate at each additional base of sequencing, the raw count of sequences is lower for the 20-base data. A total of 2,635,293 17-base and 2,259,286 20-base signatures were produced that corresponded to 30,737 and 26,878 distinct sequences, respectively (Table 1A-C). This represents a discovery rate or average raw abundance value of approximately one distinctive sequence for every $\sim 49$ sequenced cDNA tags.

Initially, to link the MPSS signatures to predicted gene annotations, all sites ("GATC") that could potentially produce an MPSS signature were identified from the available Vitis Unigene dataset in public databases. This comprised 14,658 contigs (1,307 from non-vinifera Vitis species) and 14,931 singletons (1,080 from non-vinifera Vitis species). All potential signatures starting with the GATC anchor sequence were extracted from both sense and antisense directions of the grape sequences. A total of 84,834 and 48,490 distinct 17-base potential signatures were identified, respectively, in contigs and singletons of this version of the Vitis cDNA data. When both datasets were combined, the total number of unique genomic signatures equaled 123,563. The total number of in silico-extracted distinct MPSS signatures is approximately six-fold lower than the 753,894 distinct "genomic" MPSS signatures reported for the completed Arabidopsis sequence [11], 
Table I: Summary statistics of raw 17- and 20-base MPSS signatures from grape berries.

\begin{tabular}{|c|c|c|c|c|c|c|c|c|}
\hline \multirow[b]{2}{*}{ Sequencing frame } & \multicolumn{2}{|c|}{ I7-base signatures } & \multicolumn{2}{|c|}{ 20-base signatures } & & & & \\
\hline & Absolute & $\%$ of Total & Absolute & $\%$ of Total & & & & \\
\hline 2-step run & $1,194,288$ & $45.3 \%$ & $1,002,346$ & $44.4 \%$ & & & & \\
\hline 4-step run & $\mathrm{I}, 44 \mathrm{I}, 005$ & $54.7 \%$ & $1,256,940$ & $55.6 \%$ & & & & \\
\hline \multicolumn{9}{|l|}{ B. Single filter results. } \\
\hline & \multicolumn{2}{|c|}{ I7-base signatures } & \multicolumn{2}{|c|}{ 20-base signatures } & & & & \\
\hline Reliability Filter ${ }^{\mathbf{a}}$ & Count & Proportion & Count & Proportion & & & & \\
\hline $\mathrm{R}$ & 17,976 & $58.5 \%$ & 15,699 & $58.4 \%$ & & & & \\
\hline $\mathrm{nR}$ & $|2,76|$ & $41.5 \%$ & 11,179 & $41.6 \%$ & & & & \\
\hline \multicolumn{9}{|l|}{ Significance Filter } \\
\hline S & 16,029 & $52.1 \%$ & 13,817 & $51.4 \%$ & & & & \\
\hline nS & 14,708 & $47.9 \%$ & $|3,06|$ & $48.6 \%$ & & & & \\
\hline \multicolumn{9}{|l|}{ C. Combined filter results. } \\
\hline & \multicolumn{2}{|c|}{ I7-base Total } & \multicolumn{2}{|c|}{ I7-base Distinct } & \multicolumn{2}{|c|}{ 20-base Total } & \multicolumn{2}{|c|}{ 20-base Distinct } \\
\hline Filter categories $^{a}$ & Absolute & $\%$ of Total & Count & $\%$ of Total & Absolute & $\%$ of Total & Count & $\%$ of Total \\
\hline RS & $2,550,024$ & $96.8 \%$ & 13,586 & $44.2 \%$ & $2,187,369$ & $96.8 \%$ & 11,874 & $44.2 \%$ \\
\hline $\mathrm{RnS}$ & 17,862 & $0.7 \%$ & 4,390 & $14.3 \%$ & 14,958 & $0.7 \%$ & 3,825 & $14.2 \%$ \\
\hline $\mathrm{nRS}$ & 47,346 & $1.7 \%$ & 2443 & $7.9 \%$ & 39,338 & $1.7 \%$ & 1943 & $7.2 \%$ \\
\hline$n R n S$ & 20,061 & $0.8 \%$ & 10,318 & $33.6 \%$ & $17,62 \mid$ & $0.8 \%$ & 9,236 & $34.4 \%$ \\
\hline TOTAL & $2,635,293$ & $100.0 \%$ & 30,737 & $100.0 \%$ & $2,259,286$ & $100.0 \%$ & 26,878 & $100.0 \%$ \\
\hline
\end{tabular}

\footnotetext{
"Absolute" indicates the total number of successful sequencing reads, while "count" or "distinct" indicates the number of different sequences. a $\mathrm{R}=$ reliable, $\mathrm{nR}=$ non-reliable, $\mathrm{S}=$ significant, $\mathrm{nS}$ = non-significant, $\mathrm{RS}=$ reliable and significant, $\mathrm{RnS}=$ reliable and non-significant, $\mathrm{nRS}=$ nonreliable and significant, $\mathrm{nRnS}=$ non-reliable and non-significant.
}

reflecting the incomplete nature of the grape EST dataset and the lack of intergenic and intron sequences.

Observed MPSS signatures were classified based on the output of "reliability" and "significance" filters [11]. The purpose of these filters is to separate high quality data, which is represented by signatures encountered above specified frequency thresholds, from background signal generated by very low abundance MPSS signatures. As with other MPSS datasets, the grape library was generated from four sequencing runs representing two sequencing frames [11]. There were two runs for each of the "twostep" and "four-step" sequencing frames. The reliability filter asks whether a signature is present in more than one sequencing run (of the four total runs); signatures observed in more than one run are considered "reliable". The significance filter identifies as "significant" only those signatures with a normalized abundance greater than three transcripts per million (TPM). The classifications of 17- and 20-base expressed signatures in terms of reliability and significance are shown in Tables $1 \mathrm{~A}-\mathrm{C}$ and 2; $96.8 \%$ of all MPSS signatures corresponded to the "reliable" and "significant" category, consistent with an extremely low abundance for signatures not passing the filters. This value is similar to the $97.5 \%$ reported for the Arabidopsis MPSS dataset [11]. Among MPSS signatures with exact sequence matches to EST contigs (Table 2A-B) and singletons (Table 2C-D), unique "reliable" and "significant" signatures represented the largest category (more than $60 \%$ of the unique signatures).

Expressed signatures were mapped to grape EST contigs and singletons based on exact matches to the in silico extracted "potential signatures" (see above). A total of 
Table 2: Distinct MPSS signatures matching EST contigs or singletons classified based on "reliability" and "significance" filters.

A. Filter results for II,345 I7-base signatures matching EST contigs.

\begin{tabular}{ccc}
\hline & $\begin{array}{c}\text { Significant } \\
8,012(66.2 \%)\end{array}$ & $\begin{array}{c}\text { Non-significant } \\
4,094(33.8 \%)\end{array}$ \\
\hline Reliable & $7,686(63.5 \%)$ & $1,734(14.3 \%)$ \\
$9,420(77.8 \%)$ & 6,519 contigs & 1,235 contigs \\
Non-reliable & $326(2.7 \%)$ & $2,360(19.5 \%)$ \\
$2,686(22.2 \%)$ & 632 contigs & 2,276 contigs \\
\hline
\end{tabular}

B. Filter results for 10, I 79 20-base signatures matching EST contigs.

\begin{tabular}{ccc}
\hline & $\begin{array}{c}\text { Significant } \\
7,053(65.3 \%)\end{array}$ & $\begin{array}{c}\text { Non-significant } \\
3,751(34.7 \%)\end{array}$ \\
\hline Reliable & $6,698(61.1 \%)$ & $1,473(13.6 \%)$ \\
$8,171(75.6 \%)$ & 5,830 contigs & 1,490 contigs \\
Non-reliable & $355(3.3 \%)$ & $2,278(21.1 \%)$ \\
$2,633(24.4 \%)$ & 386 contigs & 2,155 contigs \\
\hline
\end{tabular}

C. Filter results for 3,889 I7-base signatures matching EST singletons.

\begin{tabular}{ccc}
\hline & $\begin{array}{c}\text { Significant } \\
2,700(64.6 \%)\end{array}$ & $\begin{array}{c}\text { Non-significant } \\
1,477(35.4 \%)\end{array}$ \\
\hline Reliable & $2,587(61.9 \%)$ & $638(15.3 \%)$ \\
$3,225(77.2 \%)$ & 2,423 singletons & 663 singletons \\
Non-reliable & $113(2.7 \%)$ & $839(20.1 \%)$ \\
$952(22.8 \%)$ & 127 singletons & 857 singletons \\
\hline
\end{tabular}

D. Filter results for 3,367 20-base signatures matching EST singletons.

\begin{tabular}{ccc}
\hline & $\begin{array}{c}\text { Significant } \\
2,318(64.4 \%)\end{array}$ & $\begin{array}{c}\text { Non-significant } \\
1,282(35.6 \%)\end{array}$ \\
\hline Reliable & $2,207(61.3 \%)$ & $499(13.9 \%)$ \\
$2,706(75.2 \%)$ & 2,096 singletons & 511 singletons \\
Non-reliable & $111(3.1 \%)$ & $783(21.8 \%)$ \\
$894(24.8 \%)$ & 128 singletons & 780 singletons
\end{tabular}

Percentages refer to the total distinct signatures. Filters are described in the text, and are as defined in Meyers et al., [ $1 \mathrm{I}]$. In parts A and B, the number of EST contigs matched was out of a total of 6,430 unique contigs matched by 17-base signatures or 5,83 I by 20 -base signatures; signatures from different filter categories may match to the same contig (see Additional file IA-2 and Table 3 for details). In parts C and $D$, the number of EST singletons matched was out of a total of 2,190 unique singletons matched by 17 -base signatures or 2,097 by 20-base signatures; signatures from different filter categories may match to the same singleton (see Additional file IA-2 and Table 3 for details).

5,794 and 5,407 contigs were matched by expressed reliable and significant 17-base and 20-base MPSS signatures, respectively (see Additional file 1A-2). This represented, on average, more than $40 \%$ of all known Vitis sp. genes. On the other hand, only $14 \%$ of singletons in the Vitis sp. EST set were matched by MPSS signatures (Table 2C and
2D). The vast majority of the unmatched Vitis $s p$ sequences had in silico potential signatures that were not detected in the MPSS data. It is possible that the corresponding genes were not expressed in this sample; alternatively, unmatched contig and singleton EST sequences may represent 5 ' reads of cDNA clones, and thus fail to represent 3 ' regions where the majority of MPSS signatures originate. The disproportionate representation of singleton ESTs among the unmatched set is consistent with this later interpretation, because singleton ESTs in the Vitis dataset are more often the product of 5' sequencing reactions.

Most signatures matched a single contig or singleton, while $40 \%$ matched two or more [see Additional file 1A2]. In excess of $70 \%$ of matched contigs and singletons showed a one-to-one assignment to a reliable and significant MPSS signature (Figure 1) [see Additional file 3]. The remaining sequences had one-to-many assignments of up to a maximum of 16 different signatures to a single contig [see Additional file 4]. Sequences of 17-20 bp are rarely duplicated by chance in unrelated genes [7] [see Additional file 5]. Instead, biological factors involving gene duplication or transcript processing may complicate the unambiguous assignment of signatures to transcripts. Thus, gene family members with high sequence similarity are likely to yield distinct transcripts containing the same signature, while the use of multiple polyadenylation sites or alternative splice site selection can yield multiple signatures from the same transcription unit. To estimate the frequency of alternative termination, a subset of 5,145 contigs was properly aligned in their $5^{\prime}$ to 3 ' orientation. From this subset, 975 contigs matched by at least two MPSS signatures were identified. The abundance counts of 17-nucleotide significant and reliable MPSS signatures were transformed to relative frequency values and the location of each signature was plotted along the 3 '-to-5' axis for each of the 975 contigs (Figure 2). The signature frequency per contig decreased exponentially from the 3 'to-5' direction. On average, $\sim 70 \%$ of all signatures originate from the 3 ' most GATC site, while only $29 \%$ and $\sim 14 \%$ of signatures originate from the second and third 3 most positions (further 5'), respectively. Therefore, most of the transcripts matched by MPSS are the product of polyadenylation at the most distal of all recorded 3' sites. It is possible, however, that the MPSS signatures that did not match ESTs (contigs or singletons) are derived from longer 3' ends for which transcript sequence was not available.

\section{Analysis of sense-antisense expression}

Approximately $15 \%$ and $11 \%$ of the EST contigs and singletons, respectively, were matched by MPSS signatures in both sense and antisense orientations (Tables 3A-B). The MPSS signature frequencies were much higher on the 
A

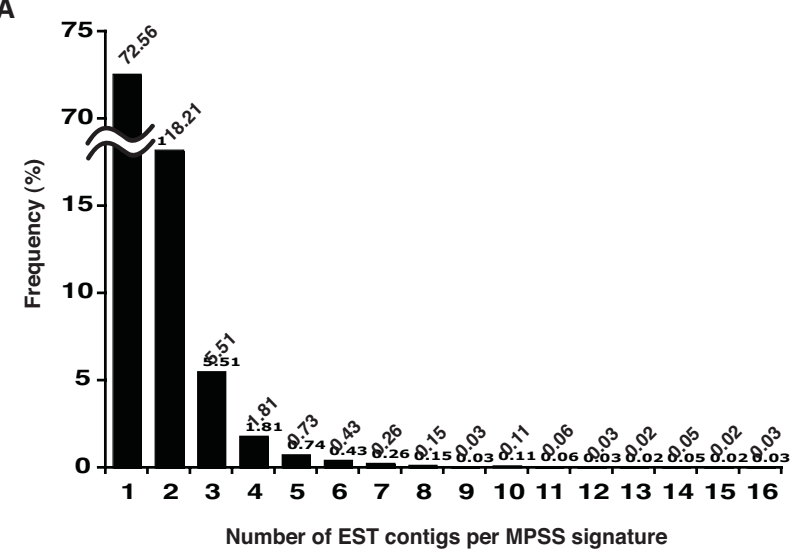

B

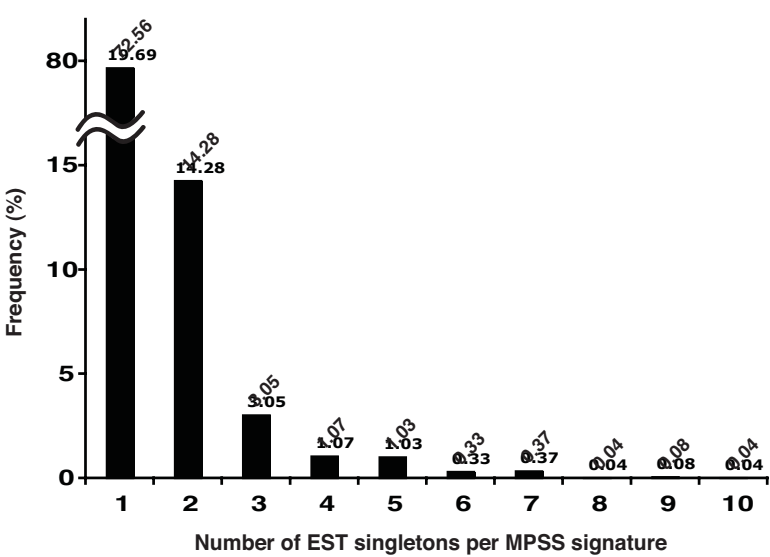

Figure I

Frequency distribution of grape ESTs matched by filtered MPSS signatures. Reliable and significant MPSS signatures were matched to EST contigs and EST singletons. UP to 16 and 10 MPSS signatures matched to one EST contig and singleton, respectively. The proportion of the number of MPSS signatures matching to (A) EST contigs and (B) EST singletons are represented by the bar graph.

sense strand for some sequences, while other sequences had higher MPSS abundances on the antisense strand [see Additional file 6]. Contigs matched in both orientations represented $\sim 12 \%$ of the known berry transcriptome (of a total of 7,828 including contigs derived from EST sequenced and cloned from cDNA libraries other than green stage II), with the 2,891 MPSS signatures matching these contigs representing $\sim 52 \%$ of the total MPSS abundance. It is possible that the sense-antisense transcript pairs are an important transcriptional feature which could provide a mechanism for post-transcriptional gene silencing [12] during this dynamic phase of berry development. Functional categorization of these contigs showed no particular overrepresented category (Figure 3). Moreover, none of these contigs had significant identifiable tBLASTx

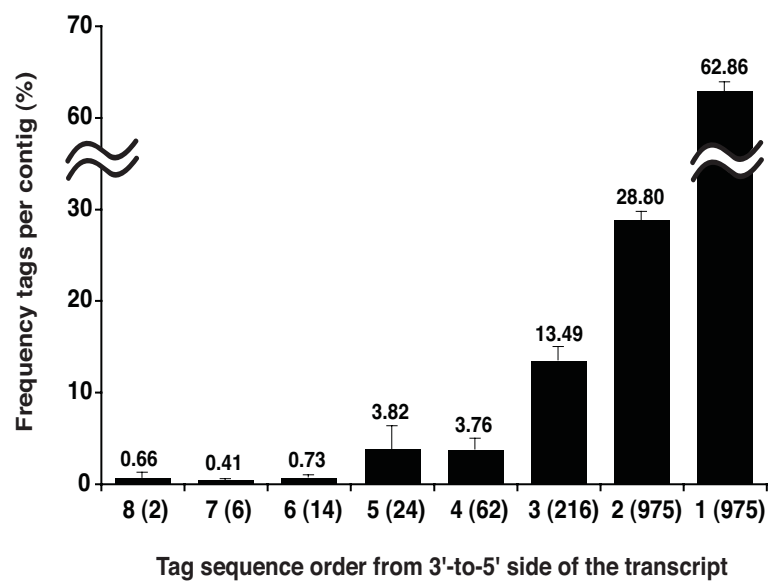

Figure 2

Frequency of reliable and significant I 7-mer MPSS signatures in a subset of 5'-to-3' oriented contigs. Signatures were mapped based on their location relative to the 3 ' end of the EST contigs. Most signatures were found at the 3'-most Dpnll site, indicated as position \#I on the $\mathbf{x}$-axis.

However, expressed MPSS signatures were found as far 5 ' as eighth Dpnll site from the $3^{\prime}$ end of the contig.

hits in both reading frame orientations, suggesting protein coding is a property of only one strand. It is possible that anti-sense transcripts could result from overlapping 3'UTRs of adjacent genes, or from transcription of an overlapping non-coding RNA.

\section{Expression profiles determined by EST and MPSS abundances}

To quantify gene expression levels, we used the relative abundance of the 7,686 reliable and significant 17-base MPSS signatures from the stage II berry library. These signatures represent the most robust subset of the MPSS expression data. Although the remaining 1,734 reliable but not significant signatures were not considered in this analysis, prior analysis suggests that these signatures are likely to represent genuine transcripts expressed at very low levels [11]. The transcripts represented by these signatures may be expressed at higher levels in different specific cells or tissue layers that were not sampled.

The MPSS sequences provide an inventory of the transcript population in a given organ or tissue that can be sorted based on abundance. This data is particularly powerful when aligned with EST data from related tissues, as it allows sorting based on abundance and predicted gene function. The MPSS-matched set of 5,791 grape EST contigs are derived from a series of cDNA libraries that survey several stages of plant development, as well as responses to biotic and abiotic stress [4]. Off these, 4,753 contigs contained ESTs derived from one or more grape berry tis- 
Table 3: Matched and un-matched Vitis EST contig and singletons.

\begin{tabular}{|c|c|c|c|c|}
\hline \multicolumn{5}{|l|}{ A. EST contigs. } \\
\hline \multirow[b]{2}{*}{ Categorya } & \multicolumn{2}{|c|}{ I7-mer } & \multicolumn{2}{|c|}{ 20-mer } \\
\hline & Count & Freq & Count & Freq \\
\hline $5^{\prime}$ and $3^{\prime}$ & 942 & $6.4 \%$ & 736 & $5.0 \%$ \\
\hline $5^{\prime}$ or $3^{\prime}$ & 5,488 & $37.4 \%$ & 5,095 & $34.8 \%$ \\
\hline Subtotal & 6,430 & $43.9 \%$ & 5,831 & $39.8 \%$ \\
\hline With tag but no match & 6,875 & $46.9 \%$ & 7,474 & $51.0 \%$ \\
\hline Without tags & 1,353 & $9.2 \%$ & 1,353 & $9.2 \%$ \\
\hline Subtotal & 8,228 & $56.1 \%$ & 8,827 & $60.2 \%$ \\
\hline Total & 14,658 & $100.0 \%$ & 14,658 & $100.0 \%$ \\
\hline
\end{tabular}

B. EST singletons.

\begin{tabular}{|c|c|c|c|c|}
\hline \multirow[b]{2}{*}{ Category ${ }^{a}$} & \multicolumn{2}{|c|}{ 17-mer } & \multicolumn{2}{|c|}{ 20-mer } \\
\hline & Count & Freq & Count & Freq \\
\hline $5^{\prime}$ and $3^{\prime}$ & 238 & $1.6 \%$ & 263 & $1.8 \%$ \\
\hline $5^{\prime}$ or $3^{\prime}$ & 1,952 & $13.3 \%$ & 1,834 & $12.5 \%$ \\
\hline Subtotal & 2,190 & $14.9 \%$ & 2,097 & $14.3 \%$ \\
\hline With tag but no match & 9,074 & $61.8 \%$ & 9,167 & $62.4 \%$ \\
\hline Without tags & 3,667 & $25.0 \%$ & 3,667 & $25.0 \%$ \\
\hline Subtotal & $|2,74|$ & $86.8 \%$ & 12,834 & $87.4 \%$ \\
\hline Total & $|4,93|$ & $100.0 \%$ & $|4,93|$ & $100.0 \%$ \\
\hline
\end{tabular}

a Categories are as follows: " 5 ' and 3"' indicates contigs matched by reliable and significant (RS) tags in both sense and antisense orientation simultaneously; " 5 ' or 3"' indicates contigs matched in their sense or antisense orientation but not both; "with tag but no match" indicates contigs with in silico identified GATC tag sites but without sequenced signatures (the presence of a Dpnll site but no matching MPSS tag, see materials and methods for details); and "without tags" indicates contigs lacking GATC sites.

sues, while 1,038 contigs were composed of ESTs from other grape tissues but not from berries (Table 4A). A total of 1,242 EST contigs matched by MPSS signatures were from ESTs found in only a single grape tissue; of these, 555 corresponded to berry-specific EST contigs. The remaining contigs were exclusively derived from leaves, flowers, petioles, stems, buds and even roots. The remaining 4,548 cDNA contigs and sequences were detected in two or more grape organs (Table 4A). Only three MPSSmatched EST contigs were found in all seven of the grape cDNA libraries. In a similar analysis of the EST singletons, the vast majority corresponded to transcripts previously observed exclusively in berry cDNA libraries, but only 207 were stage II berries (Table 4B). Among the contigs and singletons not previously associated with berry libraries were those derived from flower and leaf cDNA libraries. MPSS signatures provided valuable information to confirm the presence and relative transcriptional levels of transcripts. Many of these transcripts may have been previously mistakenly identified as tissue-specific based on EST data only because EST sequencing was not deep enough to detect these low abundance transcripts in different tissues. The MPSS data demonstrate that the inventory of genes in a given tissue is complex and there may be substantially more overlap in diverse tissues than previously characterized, and this can be identified only by sequencing ESTs at a very deep level.

One advantage of tag-based transcriptional profiling technologies such as ESTs, SAGE and MPSS is that the targets are not preselected prior to analysis. While the discovery rate of new transcripts using ESTs-based approaches is limited by the extent of sequencing effort and redundancy within a given cDNA library, unmatched or low abundance MPSS signatures could be used as primers for PCR based methods to expand the current set of known genes for Vitis [13]. There were 18,631 distinct 17-base MPSS signatures that did not match known grape EST sequences, of which 5,900 were both significant and reliable; these are most likely to represent novel genes not previously identified as transcribed or transcriptional variants. We tested this hypothesis by using available sequence of the grape genome, composed of 57,662 contigs containing $487,125,096$ base pairs [14]. In total, 20,661 17-mer and 17,867 20-mer distinct MPSS signatures matched to genome contig sequences. Among these, there were 9,125 and 7,771 distinct 17-mer and 20-mer MPSS signatures that matched only genomic contigs and not ESTs. Taking the 17-mer signatures as the benchmark, the MPSS data reveal $44 \%$ more transcript diversity than recorded in the existing public EST resource.

In silico expression profiles resulting from EST (Table 5) and MPSS signature frequencies (Table 6) showed both differences and commonalities in the relative abundance of the top-ranked genes. For example, a common feature of both datasets is the relative high abundance of several chitinases, metallothionein-like and storage proteins, as well as a putative transcription factor and an elongation factor $1-\alpha$. On the other hand, two hexameric polyubiquitins and a plasma membrane aquaporin were among the top ranked genes based on MPSS signatures but not based on EST counts, and the opposite was true (present among top ESTs, not among MPSS signatures) for a nonspecific lipid transfer protein A. A similar pattern emerges from the analysis of singleton ESTs that matched abun- 


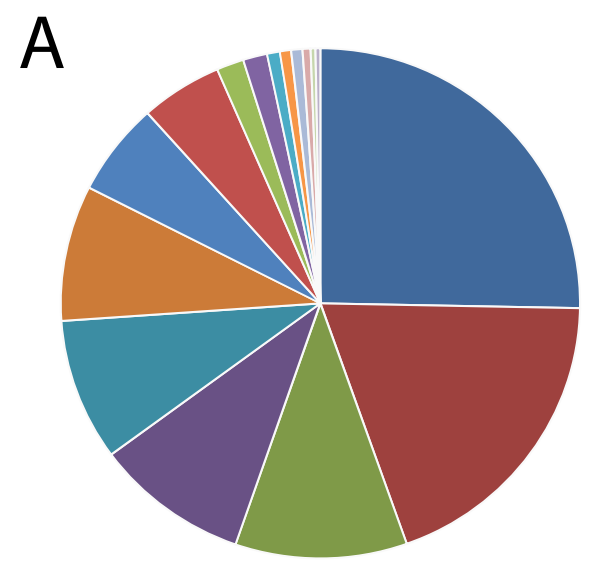

- cellular component unknown: $25.3 \%($ raw value $=9636)$

- other membranes: $19.3 \%$ (raw value $=7352$ )

- chloroplast: $10.7 \%$ ( $\mathrm{r}$ aw value $=4076$ )

- other cellular components: $9.6 \%($ raw value $=3660)$

- mitochondria: $9.0 \%$ (raw value $=3441$ )

- other intracellular components: $8.6 \%($ raw value $=3259)$

- nucleus: $5.9 \%$ (raw value $=2232$ )

v other cytoplasmic components: $5.1 \%(\mathrm{raw}$ value $=1958)$

- plastid: $1.7 \%$ ( $r$ aw value $=655)$

- ribosome: $1.5 \%$ (raw value $=565)$

" cytosol: $0.8 \%$ (raw value $=322$ )

- plasma membrane: $0.7 \%($ raw value $=270)$

" cell wall: $0.7 \%$ (raw value $=265)$

extracellular: $0.5 \%($ raw value $=178)$

(1) ER: $0.3 \%$ (raw value $=125$ )

- Golgi apparatus: $0.3 \%($ raw value $=110)$

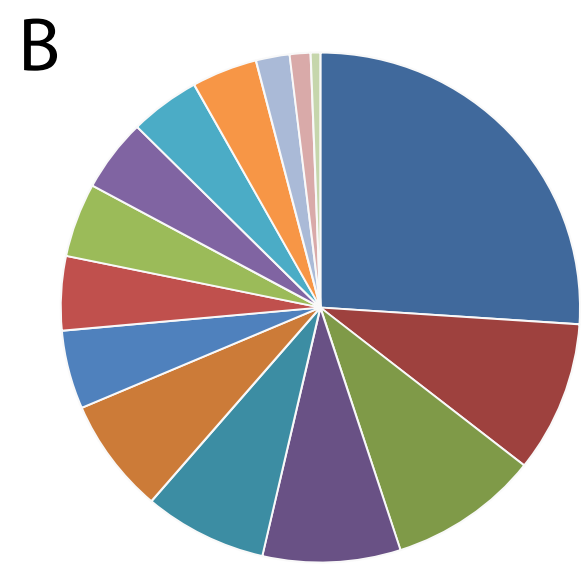

- molecular function unknown: $26.1 \%$ (raw value $=10625)$

- transferase activity: $9.6 \%$ (raw value $=3931$ )

ather enzyme activity: $9.4 \%$ (raw value $=3817$ )

- hydrolase activity: $8.6 \%$ ( raw value $=3498$ )

- kinase activity: $7.7 \%($ raw value $=3158)$

- other binding: $7.3 \%$ ( $\mathrm{raw}$ value $=2957$ )

- nucleotide binding: $5.0 \%(\mathrm{r}$ aw value $=2040)$

mother molecular functions: $4.7 \%$ (raw value $=1935$ )

- DNA or RNA binding: 4.7\% (raw value $=1903$ )

- protein binding: $4.6 \%$ ( $\mathrm{raw}$ value $=1868)$

- transporter activity: $4.4 \%$ (raw value $=1781$ )

- transcription factor activity: $4.1 \%($ raw value $=1675)$

nucleic acid binding: $2.1 \%$ ( $\mathrm{raw}$ value $=847)$

m structural molecule activity: $1.3 \%$ (raw value $=513$ )

areceptor binding or activity: $0.6 \%$ ( $\mathrm{r}$ aw value $=237$ )

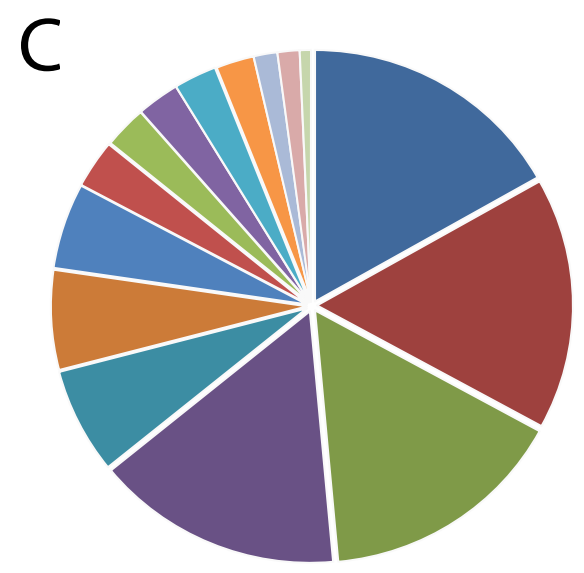

- other physiological processes: $16.8 \%$ (raw value $=11279)$

- biological process unknown: $16.2 \%($ raw value $=10869)$

- other metabolic processes: $15.6 \%($ raw value $=10433)$

- other cellular processes: $15.6 \%$ (raw value $=10418$ )

- other biological processes: $6.8 \%(\mathrm{raw}$ value $=4565)$

- protein metabolism: $6.4 \%$ (raw value $=4263$ )

- response to abiotic or biotic stimulus: $5.5 \%$ (raw value $=3651$ )

- transport: $3.1 \%$ (raw value $=2043)$

- transcription: $2.7 \%($ raw value $=1824)$

- developmental processes: $2.7 \%($ raw value $=1810)$

- response to stress: $2.7 \%$ (raw value $=1795)$

I cell organization and biogenesis: $2.4 \%(\mathrm{raw}$ value $=1622$ )

E electron transport or energy pathways: $1.5 \%$ (raw value $=1019$ )

" signal transduction: $1.4 \%($ raw value $=906)$

DNA or RNA metabolism: $0.7 \%($ raw value $=474)$

\section{Figure 3}

Functional categorization of transcripts with both sense and anti-sense MPSS signatures. EST contigs, which have both sense and anti-sense MPSS signatures, were categorized based on GO (Gene Ontology) annotation and the proportion of each category is displayed in pie-chart: (A) Cellular component, (B) Molecular function, and (C) Biological process. 
Table 4: Grape ESTs derived from distinct tissue types matched by MPSS signatures (only from Vitis vinifera).

\begin{tabular}{|c|c|}
\hline A. EST contigs. & \\
\hline Categories & Contigs \\
\hline Berry pre-veraison & 79 \\
\hline Berry veraison & 117 \\
\hline Berry post-veraison & 359 \\
\hline Subtotal berry & 555 \\
\hline Compound bud & 87 \\
\hline Flower & 132 \\
\hline Seed & I \\
\hline Petiole & 63 \\
\hline Stem & 67 \\
\hline Leaf & 332 \\
\hline Roots & 5 \\
\hline Subtotal from single organ library (excluding berry libraries) & 687 \\
\hline Subtotal from single organ librarya & 1,242 \\
\hline 2-Organs & 1,520 \\
\hline 3-Organs & 1,084 \\
\hline 4-Organs & 763 \\
\hline 5-Organs & 491 \\
\hline 6-Organs & 312 \\
\hline 7-Organs & 181 \\
\hline 8-Organs & 135 \\
\hline 9-Organs & 46 \\
\hline All I0 sampled organs & 10 \\
\hline Subtotal from multiple organ libraries ${ }^{b}$ & 4,542 \\
\hline Subtotal non-ESTs & 6 \\
\hline Total matched contigs and non-EST sequences & 5,791 \\
\hline Total matched contigs not previously associated with any berry libraryc & 1,038 \\
\hline Total matched contigs previously associated with berry librariesf & 4,753 \\
\hline A. Total matched contigs from other grape berry libraries ${ }^{d}$ & 3,439 \\
\hline B. Total matched contigs with $\geq$ I EST derived from stage II berry librariese & 1,314 \\
\hline Total unmatched contigs and non-EST sequences & 7,567 \\
\hline C. Total unmatched contigs from all libraries except (D) & 6,990 \\
\hline D. Total unmatched contigs corresponding to UCD stage II berry librariesh & 577 \\
\hline
\end{tabular}

B. EST singletons.

\begin{tabular}{lr}
\hline Categories & Contigs \\
\hline Berry pre-veraison & 177 \\
Berry veraison & 343 \\
Berry post-veraison & 389 \\
Subtotal berry & 909 \\
Compound bud & 45 \\
Flower & 231 \\
Seed & 16 \\
Petiole & 34 \\
Stem & 89 \\
Leaf & 414 \\
Roots & 49 \\
Subtotal from other libraries (excluding berry libraries) & $\mathbf{8 7 8}$
\end{tabular}


Table 4: Grape ESTs derived from distinct tissue types matched by MPSS signatures (only from Vitis vinifera). (Continued)

Total matched singletons $\quad 1,787$

A. Total matched singletons with $\geq$ I EST derived from stage II berry libraries

Total unmatched singletons

B. Total unmatched singletons from all libraries except (D)

Only 7,686 distinct, reliable and significant, 17-base MPSS signatures were used in this analysis.

a Matched contigs with at least one EST derived from berry libraries excluding those from UCD. Berry libraries in this category include multiple developmental stages and growing conditions [4].

b Matched contigs with ESTs found in CDNA libraries originated from at least two or more different grapevine organs. It may or may not simultaneously include berry libraries.

Indicates matched contigs assembled with ESTs not previously associated with berry libraries

Indicates matched contigs assembled with ESTs not previously associated with the UCD flower-berry libraries. This number includes contigs with at least one EST derived from flower-berry libraries reported by other groups.

$\mathrm{e}$ Indicates contigs containing at least one EST produced from the flower-berry UCD libraries [4].

fCorresponds to the sum of $A$ and $B$.

gTotal number of contigs and non-ESTs sequences [4] not matched by 17-mer reliable and significant tags. This value corresponds to the sum of $C$ and $\mathrm{D}$.

h Contigs with at least one EST derived from SII berry libraries [4] but not matched by 17-mer reliable and significant tags.

Table 5: Most highly expressed grape EST contigs in the grape berry stage II libraries, based on MPSS signature abundance.

\begin{tabular}{|c|c|c|c|c|c|}
\hline Contig ID & Signature abundance ${ }^{a}$ & ESTs ${ }^{b}$ & ESTsc & Total ESTs & $\begin{array}{l}\text { BlastX definition [species of closest } \\
\text { EST match] }\end{array}$ \\
\hline $1027|42,1026885,1027| 13$ & 108049 & 31 & 81 & 112 & $2 \mathrm{~S}$ albumin precursor [Vitis vinifera] \\
\hline 1027101 & 67435 & 52 & 66 & 118 & $\begin{array}{l}\text { AF449424_I I IS globulin-like protein } \\
\text { [Corylus avellana] }\end{array}$ \\
\hline $1027135,1027103,1027117$ & 60308 & 17 & 36 & 53 & $\begin{array}{l}\text { Storage protein [Corylus avellana, Coffea } \\
\text { arabica and Prunus dulcis] }\end{array}$ \\
\hline 1027226 & 46226 & 49 & 31 & 80 & conglutin gamma [Lupinus albus] \\
\hline 1027222 & 18313 & 34 & 8 & 42 & AF240006_I 7S globulin [Sesamum indicum] \\
\hline 1027379,1026935 & 17310 & 7 & 8 & 15 & plasma membrane aquaporins \\
\hline $1027444,1027445,1027446$ & 13927 & 185 & 187 & 372 & $\begin{array}{l}\text { Endochitinase and class lb chitinase [Galega } \\
\text { orientalis] }\end{array}$ \\
\hline 1027477 & 13748 & 2 & 4 & 6 & hexameric polyubiquitin \\
\hline 1027684,1027685 & 10450 & 3 & 17 & 20 & expressed protein [Arabidopsis thaliana] \\
\hline 1027454 & 6505 & 12 & 7 & 19 & $\begin{array}{l}\text { AFI2I26I_I elongation factor I-alpha I; EF- } \\
\text { I-alphal [Lilium longiflorum] }\end{array}$ \\
\hline $\begin{array}{l}\text { I027543, I027547, } 1027548 \\
\text { I027553, } 1027554\end{array}$ & 5994 & 3 & 14 & 17 & $\begin{array}{l}\text { T06239 probable glutathione transferase (EC } \\
\text { 2.5.1.18), 2,4-D inducible - soybean }\end{array}$ \\
\hline 1026907 & 5460 & 4 & & 4 & TI0I74 hypothetical protein - castor bean \\
\hline 1027486 & 5403 & 3 & 2 & 5 & hexameric polyubiquitin \\
\hline 1027455 & 4782 & & 1 & 1 & $\begin{array}{l}\text { AFI2|26I_I elongation factor I-alpha I; EF- } \\
\text { I-alphal [Lilium longiflorum] }\end{array}$ \\
\hline 1027495 & 4688 & 2 & 4 & 6 & ARF_ORYSA ADP-ribosylation factor \\
\hline 1027181 & 4668 & 2 & 1 & 3 & $\begin{array}{l}\text { TCTP_HEVBR Translationally controlled } \\
\text { tumor protein homolog (TCTP) }\end{array}$ \\
\hline $1026972,1027353,1027133$ & 4642 & 14 & 28 & 42 & $\begin{array}{l}\text { metallothionein-like protein type } 2 \text { [Persea } \\
\text { americana] }\end{array}$ \\
\hline 1027119 & 4419 & I & 6 & 7 & ATFP3 [Arabidopsis thaliana] \\
\hline 1027883 & 4390 & 1 & & 1 & LTCORII [Lavatera thuringiaca] \\
\hline 1026987 & 4208 & 36 & 22 & 58 & $\begin{array}{l}\text { AF28I656_I putative transcription factor } \\
\text { [Vitis vinifera] }\end{array}$ \\
\hline
\end{tabular}

The expression level was determined based on the signature with the maximum normalized abundance.

a The sum of abundance of matching 17-base MPSS signatures from the grape library.

b ESTs derived from stage II green, hard berries

c ESTs derived from stage II green, soft berries

d Total signatures matching contigs present in the UC Davis berry stage II libraries. 
Table 6: Most highly expressed grape EST contigs in the grape berry stage II libraries based on EST frequency.

\begin{tabular}{|c|c|c|c|c|c|}
\hline Contig ID & Signature abundance $^{a}$ & ESTs ${ }^{\mathbf{b}}$ & ESTsc & Total ESTsd & BlastX definition [species of closest EST match] \\
\hline 1027444 & 13927 & 183 & 186 & 369 & endochitinase \\
\hline 1027108 & 0 & 81 & 152 & 233 & $\begin{array}{l}\text { NLTA_RICCO NONSPECIFIC LIPID-TRANSFER PROTEIN A (NS- } \\
\text { LTP A) }\end{array}$ \\
\hline 1027101 & 67435 & 52 & 66 & 118 & AF449424_I IIS globulin-like protein [Corylus avellana] \\
\hline $1027 \mid 42$ & 108049 & 28 & 78 & 106 & $2 \mathrm{~S}$ albumin precursor [Vitis vinifera] \\
\hline 1027226 & 46226 & 49 & 31 & 80 & conglutin gamma [Lupinus albus] \\
\hline 1027166 & 0 & 30 & 44 & 74 & putative metallothionein-like protein [Vitis vinifera] \\
\hline 1027085 & 0 & 13 & 48 & 61 & putative metallothionein-like protein [Vitis vinifera] \\
\hline 1027135 & 60308 & 17 & 34 & 51 & AF449424_I IIS globulin-like protein [Corylus avellana] \\
\hline 1027222 & 18313 & 34 & 8 & 42 & AF240006_I 7S globulin [Sesamum indicum] \\
\hline 1026987 & 4208 & 23 & 14 & 37 & AF281656_I putative transcription factor [Vitis vinifera] \\
\hline 1026972 & 4642 & 10 & 13 & 23 & metallothionein-like protein type 2 [Persea americana] \\
\hline 1027300 & 0 & 14 & 7 & 21 & $\begin{array}{l}\text { Transcript Antisense to Ribosomal RNA; Tarlp [Saccharomyces } \\
\text { cerevisiae] }\end{array}$ \\
\hline 1027410 & 4208 & 13 & 8 & 21 & AF28I656_I putative transcription factor [Vitis vinifera] \\
\hline 1027454 & 6505 & 12 & 7 & 19 & $\begin{array}{l}\text { AFI2I } 26 \mid \text { II elongation factor I-alpha I; EF-I-alphal [Lilium } \\
\text { longiflorum] }\end{array}$ \\
\hline 1027053 & 120 & 4 & 14 & 18 & No hit \\
\hline 1027353 & 4642 & 4 & 14 & 18 & No hit \\
\hline 1027684 & 10450 & 3 & 15 & 18 & expressed protein [Arabidopsis thaliana] \\
\hline 1027078 & 0 & 3 & 14 & 17 & THIH_RICCO Thioredoxin H-type (TRX-H) \\
\hline 1028129 & 3736 & 2 & 15 & 17 & AFI92486_I omega-6 fatty acid desaturase [Sesamum indicum] \\
\hline 1027302 & 4075 & 13 & 3 & 16 & No hit \\
\hline
\end{tabular}

a The sum of abundance of matching 17-base MPSS signatures from the grape library.

b ESTs derived from stage II green, hard berries.

c ESTs derived from stage II green, soft berries.

d Total signatures matching contigs present in the UC Davis berry stage II libraries.

dant MPSS signatures (Table 7). Among such singleton ESTs, there were transcripts related to cell wall modification (xyloglucan-specific fungal endoglucanase inhibitor protein and an extensin-like protein), abiotic/biotic stress factors (catalase and hydroperoxide oxidase), a eukaryotic translation initiation factor and several poorly annotated transcripts.

Significant differences were observed in the relative abundance of contigs from EST or MPSS signature counts. While a total of 195 contigs accounted for approximately $50 \%$ of the ESTs sequenced from the two berry SII libraries, only 10 contigs matched an identical proportion of the filtered MPSS signatures. The top 20 contigs ranked based on MPSS frequency accounted for 410,925 (56.7\% of all sequences matching to EST contigs), suggesting a steeper curve and perhaps lower level of diversity in MPSS data. In contrast, the 20 most frequent contigs based on EST counts represented only $29.4 \%$ of the total EST for these two libraries.

As might be expected, MPSS signatures sequenced from $V$. vinifera berries stage II also matched several non-vinifera EST singletons and contigs in the Vitis Unigene set. Although the transcriptome of the non-vinifera species has been minimally characterized, a comparison of the topranked transcripts based on MPSS signature frequency
(Tables 8 and 9) showed remarkable similarities between the different species.

\section{A website for access to the grape MPSS data}

To facilitate public access and utilization of the MPSS data, we developed a database and web-based interface [15]. The database and interface is a customized version of a previously described website [16]. Unlike the Arabidopsis or rice MPSS sites which utilize the complete genomic sequence of these species, our grape database focuses on EST contigs. This required the development of specialized tools and methods. For example, the incomplete nature of ESTs required a BLAST tool that would allow the user to identify the closest grape sequence to their gene of interest. The MPSS data can be accessed by entering the grape contig identifier or EST code, the MPSS signature sequence, the grape sequence of interest, or a list of contig identifiers. The data on transcriptional activity that this website provides may be used as the starting point for analyses of individual genes or gene families in grape.

\section{Discussion}

We have explored expression patterns at a specific stage in grape berry development by comparing and combining two tag-based methods: ESTs and MPSS. Both approaches described similar patterns of transcripts abundances, although there were some clear differences perhaps associ- 
Table 7: Top 20 grape EST singletons based on MPSS signature abundance.

\begin{tabular}{|c|c|c|c|c|c|}
\hline Singleton IDs & Signature abundance ${ }^{a}$ & ESTs ${ }^{b}$ & ESTsc & Total ESTs ${ }^{d}$ & $\begin{array}{l}\text { BlastX definition [species of } \\
\text { closest EST match] }\end{array}$ \\
\hline $\begin{array}{l}\text { CB346285, CB348203, CB349257, } \\
\text { CB349340, CB350305, CB979523 }\end{array}$ & 108049 & 1 & 5 & 6 & $\begin{array}{l}\text { Albumin seed storage protein precursor } \\
\text { [Juglans regia] }\end{array}$ \\
\hline $\begin{array}{l}\text { CB346171, CB3479I2, CB349205, } \\
\text { CB349357 }\end{array}$ & 67435 & & 4 & 4 & IIS globulin \\
\hline CB347682 & 46226 & & 1 & 1 & $\begin{array}{l}\text { Xyloglucan-specific fungal } \\
\text { endoglucanase inhibitor protein } \\
\text { precursor [Lycopersicon esculentum] }\end{array}$ \\
\hline $\begin{array}{l}\text { CB346916, CB347II I, CB347I60, } \\
\text { CB3472 I0, CB3479I6, CB34827I, } \\
\text { CB348487, CB348646, CB349834, } \\
\text { CB976447 }\end{array}$ & 33100 & I & 9 & 10 & $\begin{array}{l}\text { NLTA_RICCO Nonspecific lipid- } \\
\text { transfer protein A (NS-LTP A) } \\
\text { (phospholipid transfer protein) (PLTP) }\end{array}$ \\
\hline $\begin{array}{l}\text { CB346008, CB348II I9, CB348425, } \\
\text { CB348509, CB348553, CB349918 }\end{array}$ & 13927 & & 6 & 6 & $\begin{array}{l}\text { Chitinases [Arabis fecunda, Glycine } \\
\text { max, Vitis vinifera, Fragaria } \times \text { ananassa, } \\
\text { chic pea] }\end{array}$ \\
\hline CВ346025, СВ976380 & 5234 & I & 1 & 2 & $\begin{array}{l}\text { Chitinase [Oryza sativa (indica cultivar- } \\
\text { group)] }\end{array}$ \\
\hline CB347884 & 4642 & & I & 1 & $\begin{array}{l}\text { A34I3I metallothionein I homolog - } \\
\text { spotted monkey flower }\end{array}$ \\
\hline CB348305 & 4208 & & I & 1 & $\begin{array}{l}\text { AF28I656_I putative transcription } \\
\text { factor [Vitis vinifera] }\end{array}$ \\
\hline CB978988 & 2805 & I & & 1 & AF236127_I catalase [Vitis vinifera] \\
\hline CB34789I & 2746 & & 1 & 1 & $\begin{array}{l}\text { IF52_NICPL Eukaryotic translation } \\
\text { initiation factor } 5 \mathrm{~A}-2 \text { (elF-5A) (elF-4D) }\end{array}$ \\
\hline CB347634 & 2724 & & 1 & 1 & $\begin{array}{l}\text { Hydroperoxide lyase [Nicotiana } \\
\text { attenuata] }\end{array}$ \\
\hline CB348030 & 2219 & & 1 & 1 & $\begin{array}{l}\text { S49422 IIS globulin seed storage } \\
\text { protein - prince\&apos;s feather }\end{array}$ \\
\hline CB346850, CB350I75 & 2084 & & 2 & 2 & $\begin{array}{l}2 \mathrm{~S} \text { albumin [Vitis vinifera and Helianthus } \\
\text { annus] }\end{array}$ \\
\hline CB97756I & 1726 & I & & 1 & $\begin{array}{l}\text { AFI2|26I_I elongation factor I-alpha } \\
\text { I; EF-I-alpha I [Lilium longiflorum] }\end{array}$ \\
\hline CB978I60 & 1714 & 1 & & 1 & $\begin{array}{l}\text { expressed protein [Arabidopsis } \\
\text { thaliana] }\end{array}$ \\
\hline CB977027 & 1343 & I & & 1 & No Hit \\
\hline СВ976255 & 1267 & I & & 1 & $\begin{array}{l}\text { Expressed protein; protein id: } \\
\text { At3g52500.I, supported by cDNA: } \\
\text { [Arabidopsis thaliana] }\end{array}$ \\
\hline CB346I04, CB347550 & 1049 & & 2 & 2 & endochitinase \\
\hline CB347847 & 983 & & 1 & I & $\begin{array}{l}\text { S54I } 57 \text { extensin-like protein - cowpea } \\
\text { (fragment) }\end{array}$ \\
\hline CB347925, CB349273 & 942 & & 2 & 2 & $\begin{array}{l}\text { S51942 prunin } 2 \text { precursor - almond } \\
\text { (fragment) }\end{array}$ \\
\hline
\end{tabular}

a The sum of abundance of matching 17-base MPSS signatures (reliable and significant) from the grape library.

b ESTs derived from stage II green, hard berries

c ESTs derived from stage II green, soft berries

d Total signatures matching contigs present in the UC Davis berry stage II libraries.

ated with the methods themselves. In principle, due to deeper sequencing, the MPSS data should provide a more thorough and quantitative representation of the absolute transcript population in terms of representation and relative abundance than that from ESTs $[7,11]$. This is particularly true when the number of cDNA clones sequenced from any given library is low or for genes expressed at only low levels in the sampled tissues. For the EST frequency to represent the absolute transcript frequency, sequencing efforts must be large and sampling must be unbiased. The goal of achieving saturation for libraries constructed from a specific tissue may be overcome by combining library information available in public domain databases, if those resources are large enough. However, the different protocols used for library construction and EST sequencing, the lack of complete control of growing conditions, genotype and even standardized guidelines to describe a particular stage in development, makes it difficult to achieve unbiased sampling. On the other hand, MPSS analysis is also subject to bias. For example, some highly transcribed genes (based on EST frequency analysis) were unmatched by any MPSS signatures, possibly due to either the lack of a GATC site in 
Table 8: Most highly expressed grape EST contigs from non-vinifera libraries based on MPSS signature abundance.

\begin{tabular}{|c|c|c|c|}
\hline Contig ID & Signature abundance ${ }^{a}$ & Species ${ }^{b}$ & BlastX definition [species of closest EST match] \\
\hline 1025631,1026062 & 17310 & Vae, Vru $\times$ Var & AFI4I899_I putative aquaporin PIPI-3 [Vitis berlandieri $\times$ Vitis rupestris] \\
\hline 1025594 & 13748 & Vae & UQFS ubiquitin precursor - common sunflower (fragment) \\
\hline 1025587 & 6505 & Vae & AFI2126I_I elongation factor I-alpha I; EF-I-alphal [Lilium longiflorum] \\
\hline 1025940 & 5994 & Vru $\times$ Var & T06239 probable glutathione transferase (EC 2.5.1.18), 2,4-D inducible - soybean \\
\hline $102564 \mid$ & 5460 & Vae & TI0I74 hypothetical protein - castor bean \\
\hline 1026041 & 5403 & Vru $\times$ Var & T5J8.2I polyubiquitin (UBQ I4) identical to GI:I66795 [N. sylvestris] \\
\hline 1026403 & 5403 & Vru $\times$ Var & CI7L7.6 T32N4.13 score $=526.5, E=1.9 \mathrm{e}-154, \mathrm{~N}=3$ \\
\hline 1025620 & 4688 & Vae & ARF_ORYSA ADP-ribosylation factor \\
\hline 1025855 & 4642 & Vru $\times$ Var & MTI_CASGL Metallothionein-like protein I (MT-I) \\
\hline 1025856 & 4642 & Vru $\times$ Var & No hit \\
\hline 1025842,1025843 & 4208 & Vru $\times$ Var & AF28I656_I putative transcription factor [Vitis vinifera] \\
\hline 1026742 & 3463 & Vru $\times$ Var & FI2FI.24 putative aspartic proteinase similar to GB:AAC49730 \\
\hline 1026015 & 2805 & Vru $\times$ Var & TI2J5.2 M4EI3.I 40 catalase \\
\hline 1026595 & 2746 & Vru $\times$ Var & $\begin{array}{l}\text { FI6A I4.17 F7A } 19.4 \text { initiation factor 5A-4 identical to initiation factor 5A-4 [A. } \\
\text { thaliana] }\end{array}$ \\
\hline I02557।, 1025572 & 2435 & Vae & T09838 chlorophyll a/b binding protein precursor - upland cotton chloroplast \\
\hline 1026113 & 2355 & Vru $\times$ Var & $\begin{array}{l}\text { T23EI8.12 dehydrin, putative similar to dehydrin GI:975646 from [Arabidopsis } \\
\text { thaliana] }\end{array}$ \\
\hline 1025893 & 2164 & Vru $\times$ Var & No hit \\
\hline 1025946 & 1877 & Vru $\times$ Var & dormancy-associated protein -related [Arabidopsis thaliana] \\
\hline 1025914 & 1840 & Vru $\times$ Var & cyclophilin [Ricinus communis] \\
\hline 1026217 & 1726 & Vru $\times$ Var & AFI2126I_I elongation factor I-alpha I; EF-I-alpha I [Lilium longiflorum] \\
\hline
\end{tabular}

a The sum of abundance of matching 17-base MPSS signatures from the grape library.

b Species abbreviations are as follows: Vae = Vitis aestivalis; Vru $\times$ Var $=$ D8909-I5 (Vitis rupestris 'A. de Serres' $\times$ Vitis arizonica)

Table 9: Most highly expressed grape EST contigs from non-vinifera libraries based on MPSS signature abundance.

\begin{tabular}{|c|c|c|c|}
\hline Contig ID & Signature abundance ${ }^{a}$ & Species & Blast $X$ definition \\
\hline CB518189 & 17310 & $V_{c i} \times V_{r u}$ & AFI4I899_I putative aquaporin PIPI-3 [Vitis berlandieri $\times$ Vitis rupestris] \\
\hline CF205324 & 13748 & Vru $\times$ Var & polyubiquitin [Elaeagnus umbellata] \\
\hline CB288827 & 10450 & Vae & expressed protein [Arabidopsis thaliana] \\
\hline CF203205 & 5994 & Vru $\times$ Var & $\begin{array}{l}\text { GTXA_TOBAC PROBABLE GLUTATHIONE S-TRANSFERASE PARA (AUXIN- } \\
\text { REGULATED PROTEIN PARA) (STR246C PROTEIN) }\end{array}$ \\
\hline CB5I8203 & 4688 & $\mathrm{Vci} \times \mathrm{Vru}$ & ADP-ribosylation factor [Arabidopsis thaliana] \\
\hline CB518I74 & 4668 & Vci $\times$ Vru & TCTP_ORYSA Translationally controlled tumor protein homolog (TCTP) \\
\hline CB518217 & 4642 & $V_{c i} \times V_{r u}$ & MTI_CASGL Metallothionein-like protein I (MT-I) \\
\hline CF206203 & 4208 & Vru $\times$ Var & AF28I656_I putative transcription factor [Vitis vinifera] \\
\hline CF202582 & 3036 & Vru $\times$ Var & No hit \\
\hline CF568957 & 2435 & Vsh & T09838 chlorophyll a/b binding protein precursor - upland cotton chloroplast \\
\hline CF204795 & 2164 & Vru $\times$ Var & phase-change related protein [Quercus robur] \\
\hline CF568866 & 2055 & Vsh & DNJH_CUCSA DnaJ protein homolog (DNAJ-I) \\
\hline CB518I64 & 1726 & $V_{c i} \times V_{r u}$ & AFI2I26I_I elongation factor I-alpha I; EF-I-alphal [Lilium longiflorum] \\
\hline CF5689I2, CF568996 & 1354 & Vsh & $\begin{array}{l}\text { RBS_FAGCR Ribulose bisphosphate carboxylase small chain, chloroplast precursor } \\
\text { (RuBisCO small subunit) }\end{array}$ \\
\hline CB518167 & 913 & Vci $\times$ Vru & 60S ribosomal protein L26 (RPL26A) [Arabidopsis thaliana] \\
\hline CB289025 & 866 & $\mathrm{Vae}$ & seed specific protein BnI5DIB [Brassica napus] \\
\hline CB602249 & 846 & Vae & No hit \\
\hline CB289590 & 802 & Vae & $60 S$ ribosomal protein L27a [Panax ginseng] \\
\hline CB288422 & 779 & Vae & 60S ribosomal protein LI9 (RPLI9B) [Arabidopsis thaliana] \\
\hline CB5I820I & 714 & $V_{c i} \times V_{r u}$ & ARF_ORYSA ADP-ribosylation factor \\
\hline
\end{tabular}

a The sum of abundance of matching 17-base MPSS signatures from the grape library.

b Species abbreviations are as follows: Vae $=$ Vitis aestivalis; Vru $\times$ Var $=$ D8909-I5 (Vitis rupestris 'A. de Serres' $\times$ Vitis arizonica), Vci $\times$ Vru $=$ Vitis cinerea $\times$ Vitis rupestris, Vsh $=$ Vitis shutthelworthii. 
the sequence or a technological artifact. The lack of suitable DpnII sites in some Arabidopsis transcripts is one source of negative results in MPSS transcriptional profiles compared against other high-throughput technologies [17]. In addition, MPSS substantially underestimates expression for signatures either containing the recognition site for the Type IIS restriction endonuclease BbvI (used in MPSS sequencing), or signatures containing certain four-nucleotide words in the sequencing frames [11]. The formerly high cost of tag-based methods limited biological replication as part of the experimental approach; such data would be highly desirable to determine the degree of biological variation and technical noise derived from these technologies [7]. This may be more achievable with the next generation of technologies as costs are reduced. The combined application of multiple approaches for transcriptional profiling is likely to provide the most robust determination of transcript levels.

In the grape MPSS dataset, when multiple signatures matched to one contig, these usually varied significantly in abundance. However, these data were consistent with the most abundant MPSS signature derived from the predominant form of the transcript among the ESTs [1]. An assessment of alternative transcript polyadenylation based on MPSS in diverse tissues and treatments could provide insight into this mechanism of gene regulation by identifying differentially terminated transcripts. The annotation and analysis of signatures matching multiple contigs is a more difficult task, but validation of these data could be performed by using microarrays with specifically designed probes to determine the relative expression of all matched genes, or by repeating the MPSS experiment using a different "anchoring enzyme" such as NlaIII (CATG) instead of DpnII (GATC).

The occurrence of genome-wide duplications may drive genome diversification and speciation in the plant kingdom [18]. Gene- and organ-specific silencing and unequal expression levels have been reported in upland cotton for homeologous genes resulting from whole genome polyploidization [19-21] and a similar phenomenon may be the cause of yellow-seeded commercial soybean cultivars [22]. The extent to which duplication-associated changes in gene expression may be playing a role in grapevine phenotypes is largely unknown. Due to the ancestral polyploid nature of the grape genome [23-25], duplication events leading to interactions or silencing among homeologous genes may have occurred. Evidence of extensive antisense expression was identified by comparing the ESTs and MPSS transcriptional profiling data. Initial whole transcriptome analysis in mammalian systems indicated that up to $20 \%$ of all transcripts formed senseantisense (S/AS) pairs [26-31]. Recent analysis derived from a large scale mouse cDNA sequencing project [32] and a high resolution transcriptional map of human chromosomes [33] revealed that S/AS pairs exists for up to $72 \%$ and $50 \%$ of all mouse and human transcripts, respectively. S/AS frequencies observed in the berry transcriptome are similar to those reported in Arabidopsis, where approximately $22 \%$ of all known genes have tissue specific natural antisense transcript pairs [7]. Considering the unequal contribution of different genes and regions in the genome to the formation of S/AS pairs [32], whole transcriptome analysis would certainly provide a more accurate description of the extent of the phenomena in grapes than the one determined with a limited coverage of the transcriptome in this study.

Two distinct sources of native antisense expression have been identified: cis- and trans-encoded antisense [27-29]. The former correspond to transcripts derived from the opposite strand in the same genetic locus as the sense RNA. Cis-encoded antisense transcripts tend to have complete overlap with the sense strand forming long perfect match RNA duplexes [28]. Approximately $50 \%$ of senseantisense pair categories in humans fell within this category [29]. Trans-encoded antisense transcripts derive from alternative loci and tend to have partial overlap with the sense strand of the original locus $[27,28]$. The function of endogenous populations of dsRNA or small RNAs in grape remain to be elucidated with more detailed experiments, and this is best performed using short-read sequencing methods [34].

Tag-based transcriptional profiling approaches provide unique advantages for the discovery of novel expressed sequences. MPSS signatures derived from a specific stage in berry developmental revealed the existence of potentially 6,345 novel transcripts in grapes. These transcripts could be more fully identified to expand the set of known and experimentally verified Vitis genes either by PCRbased approaches [13], or ultimately aligning the signatures with grape genomic sequence. In the absence of full genome sequence information, PCR-based approaches may become particularly important for transcripts that are difficult to identify by means of EST-based approaches due to their low copy number or technical limitations of RNA-dependent cDNA synthesis. Whole genome sequencing of the $V$. vinifera genome, combined with data-rich tag-based (ESTs and MPSS signature frequencies) and microarray-based transcriptional data will greatly contribute to our understanding of the complex relationships between genome organization, transcriptional activity, and phenotypes. Because automated genome annotation systems are both error-prone and greatly improved with the incorporation of experimental data, the EST and MPSS data will prove invaluable in the coming years for gene discovery and the annotation of genomic sequences. 


\section{Conclusion}

We have performed a complete transcriptional analysis of $V$. vinifera berries in transition to the ripening stage using MPSS combined with EST data. Approximately 30,000 distinct signatures, each representing a distinct transcript, were identified from the MPSS data and the signatures were mapped onto EST sequences. The number of MPSS signatures matching to one EST ranged from one to 16 and suggests the existence of numerous alternative transcripts in $V$. vinifera. In addition, a large set of MPSS signatures that matched to the anti-sense orientation ESTs was identified. Although the existence of antisense transcripts has been reported in many plant species, this is the first data to suggest the existence of antisense transcripts in $V$. vinifera. In addition to the signatures with EST matches, large numbers of MPSS signatures which do not match to ESTs were identified. While a small proportion could be due to sequencing errors, we believe the majority of these were mainly due to the low depth of sequence coverage in the current EST dataset; support for this interpretation derives from the fact that the proportion of signatures matching $V$. vinifera sequences was nearly doubled by incorporation of whole genome sequence data. High capacity, short read sequencing technologies, in particular next generation gigabase methods, have potential to contribute an important element to ongoing annotation of the genome sequence of $V$. vinifera. The grape MPSS data is accessible from University of Delaware MPSS website [1] and the EST data sets are available through UCDavis College of Agricultural and Environmental Sciences Genomics Facility (CGF) website [35].

\section{Methods}

\section{Plant material and sampling procedures}

The cDNA used for MPSS sequencing was constructed from stage II berries (green hard) sampled from fieldgrown V. vinifera cv. Cabernet Sauvignon, clone 8 vines located in the Tyree Teaching Vineyard, UC Davis, CA. Berries were sampled from multiple clusters and from different positions in individual clusters in order to ensure a representative sample. A sub-sample of berries at this stage was used to generate a cDNA library and expressed sequence tags (ESTs), as reported previously [4]. For additional details on sample handling and storage, see Goes da Silva et al., 2005.

\section{MPSS data generation and analysis}

All MPSS was performed essentially as described previously $[5,6]$, with the library produced and sequenced at Illumina, Inc. (formerly Solexa, Inc.; Hayward, CA). The raw and normalized MPSS data are available at University of Delaware MPSS website [1]. We compared MPSS signatures to the $V$. vinifera ESTs available at UC Davis CGF website [35] and assigned signatures to each sequence for which a perfect match was identified. The number of matches of a signature to the EST dataset was recorded as the "hits" for each signature. We merged the sequencing runs and calculate a single normalized abundance as reported earlier [11]. Contig orientation in the 5'-to-3' direction was performed using batch BLASTX search and the analysis of subject indexes of the first EST and last EST for each contig. Data analysis was conducted in MS Excel (Microsoft, Seattle, WA) and SAS V.8 statistical package (The SAS Institute, Cary, NC), or in a customized MySQL database [16] and figures in SigmaPlot version 8.0 (Systat Software Inc., San Jose, CA).

\section{Authors' contributions}

AI performed research and analyzed data; $\mathrm{KN}$ performed computational research; FGdS analyzed data; DRC and BCM designed the experiments. All of the authors participated in the writing of the manuscript.

\section{Additional material}

\section{Additional file 1}

Filtered MPSS signatures matching to grape EST contigs. Table A: 17-mer signatures. Table B: 20-mer signatures

Click here for file

[http://www.biomedcentral.com/content/supplementary/14712229-8-53-S1.doc]

\section{Additional file 2}

Number of MPSS signatures matching to contigs and singletons. All the unique signatures (both 17 and 20-mer) were categorized into the following eight categories: Reliable (R), not Reliable (nR), Significant (S), not Significant (nS), Reliable and Significant (RS), Reliable but not Significant (RnS), not Reliable but significant (nRS), and not Reliable and not Significant ( $n R n S)$. The number and the frequency of the signatures in each category were identified in both sense and antisense orientation. Panel A: 17-mer MPSS signatures matched to EST contigs. Panel B: 20mer MPSS signatures matched to EST contigs. Panel C: 17-mer MPSS signatures matched to EST singletons. Panel D: 20-mer MPSS signatures matched to EST singletons.

Click here for file

[http://www.biomedcentral.com/content/supplementary/14712229-8-53-S2.xls]

\section{Additional file 3}

Iandolino. Frequency distribution of grape ESTs matched by MPSS signatures. The tables in this file show the frequency of MPSS signatures matching to ESTs. The frequency ranges from one to 16 for EST contigs (panel $A$ and $B$ ) and 1 to 10 for EST singletons (panel $C$ and D). Data in each table are categorized based on the filters we used to sort MPSS signatures: $R S$, reliable and significant; RnS, reliable but non-significant; $n R S$, nonreliable but significant; $n R n S$, non-reliable and non-significant. Panel A: 17-mer MPSS signatures matched to EST contigs. Panel B: 20-mer MPSS signatures matched to EST contigs. Panel C: 17-mer MPSS signatures matched to EST singletons. Panel D: 20-mer MPSS signatures matched to EST singletons.

Click here for file

[http://www.biomedcentral.com/content/supplementary/14712229-8-53-S3.pdf] 


\begin{abstract}
Additional file 4
Example of a grape EST contigs matched by multiple MPSS signatures. One of the EST contigs with 3 MPSS signatures matches is shown. This contig (CTG1027770) has similarity to "putative transcription factor BTF3-like mRNA". Panel A shows all the MPSS signatures identified in this contig, with the abundance level and its coordinate on the contig. Panel B displays the sequence of this contig and all the sense MPSS signatures from panel $A$ are indicated in blue. Uppercase letters indicate the predicted ORF, while lowercase letters indicate the predicted UTRs. The position of the most abundant signature (\#2) is consistent with the most3' DpnII site, the position measured by MPSS. Other signatures may result from signatures resulting from other transcripts, alternative polyadenylation or incomplete digestion during the construction of the MPSS
\end{abstract} library.

Click here for file

[http://www.biomedcentral.com/content/supplementary/14712229-8-53-S4.pdf]

\section{Additional file 5}

Occurrence of identical MPSS signatures in related and unrelated contigs. The example of MPSS signatures with multiple hits to EST contigs is shown. In this particular example, the MPSS signature "GATCAAGACTGATGAAA" (displayed in red) was identified in three EST contigs where two of them have the same annotation and the third is different. The most closely related Arabidopsis homolog along with its BLAST expected value is list at the beginning of each coding sequence.

Click here for file

[http://www.biomedcentral.com/content/supplementary/14712229-8-53-S5.pdf]

\section{Additional file 6}

EST contigs with expressed sense and antisense MPSS signatures. All the EST contigs with MPSS signatures matching to both sense and antisense orientation are displayed. Each contig was BLASTed against Arabidopsis annotation version 5 (TIGR5) and the potential function of the contigs was listed under "blastdef" along with the gene ID ("ginumber") and the BLAST expected value ("evalue"). The contigs originated from two different EST corrections (Stage II berry GH and GS) that derived from various Vitis species. The EST ID numbers for GH and GS, as well as the species name, are listed under "Berry SII-GH", "Berry SII-GS", and "SPECIES". Click here for file

[http://www.biomedcentral.com/content/supplementary/14712229-8-53-S6.xls]

\section{Acknowledgements}

We thank Huizhuan Wu and Mayumi Nakano for their work on the grape MPSS web interface, and Richi Gupta, Anna Leslie and Brian Chan for bioinformatics assistance. This work was supported by research grants from the NSF Plant Genome Research Program (awards \#0I 10528 and \#032। 437 to B.C.M.), the USDA-ARS (SCA 58-5302-2-788 to D.R.C.), and the California Department of Food and Agriculture (Contract 02-0150 to D.R.C).

\section{References}

I. Grape MPSS Database [http://mpss.udel.edu/grape/]

2. Vivier MA, Pretorius IS: Genetically tailored grapevines for the wine industry. Trends Biotechnol 2002, 20(I I):472.

3. Ollat N, Diakou-Verdin P, Carde JP, Barrieu F, Gaudillére JP, Moing A: Grape berry development: a review. Journal International des Sciences de la Vigne et du Vin 2002, 36:109-131.
4. Goes da Silva F, landolino A, Al-Kayal F, Bohlmann MC, Cushman MA Lim H, Ergul A, Figueroa R, Kabuloglu EK, Osborne C, Rowe J, Tattersall E, Leslie A, Xu J, Baek J, Cramer GR, Cushman JC, Cook DR: Characterizing the Grape Transcriptome. Analysis of Expressed Sequence Tags from Multiple Vitis Species and Development of a Compendium of Gene Expression during Berry Development. Plant Physiol 2005, 139(2):574-597.

5. Brenner S, Johnson M, Bridgham J, Golda G, Lloyd DH, Johnson D, Luo S, McCurdy S, Foy M, Ewan M, Roth R, George D, Eletr S, Albrecht G, Vermaas E, Williams SR, Moon K, Burcham T, Pallas M, DuBridge RB, Kirchner J, Fearon K, Mao J, Corcoran K: Gene expression analysis by massively parallel signature sequencing (MPSS) on microbead arrays. Nat Biotechnol 2000, 18(6):630-634.

6. Brenner S, Williams SR, Vermaas EH, Storck T, Moon K, McCollum C, Mao JI, Luo S, Kirchner JJ, Eletr S, DuBridge RB, Burcham T, Albrecht G: In vitro cloning of complex mixtures of DNA on microbeads: physical separation of differentially expressed cDNAs. Proc Natl Acad Sci USA 2000, 97(4): 1665-1670.

7. Meyers BC, Vu TH, Tej SS, Ghazal H, Matvienko M, Agrawal V, Ning J, Haudenschild CD: Analysis of the transcriptional complexity of Arabidopsis thaliana by massively parallel signature sequencing. Nat Biotechnol 2004, 22(8): I006-10II.

8. Velculescu VE, Zhang L, Vogelstein B, Kinzler KW: Serial Analysis of Gene Expression. Science 1995, 270(5235):484-487.

9. Nobuta K, Venu RC, Lu C, Belo A, Vemaraju K, Kulkarni K, Wang W Pillay M, Green PJ, Wang G, Meyers BC: An expression atlas of rice mRNAs and small RNAs. Nat Biotechnol 2007, 25(4):473.

10. Margulies M, Egholm M, Altman WE, Attiya S, Bader JS, Bemben LA Berka J, Braverman MS, Chen YJ, Chen Z, Dewell SB, Du L, Fierro JM, Gomes XV, Godwin BC, He W, Helgesen S, Ho CH, Irzyk GP, Jando SC, Alenquer MLI, Jarvie TP, Jirage KB, Kim JB, Knight JR, Lanza JR, Leamon JH, Lefkowitz SM, Lei M, Li J, Lohman KL, Lu H, Makhijani VB, McDade KE, McKenna MP, Myers EW, Nickerson E, Nobile JR, Plant R, Puc BP, Ronan MT, Roth GT, Sarkis GJ, Simons JF, Simpson JW, Srinivasan M, Tartaro KR, Tomasz A, Vogt KA, Volkmer GA, Wang SH, Wang Y, Weiner MP, Yu P, Begley RF, Rothberg JM: Genome sequencing in microfabricated high-density picolitre reactors. Nature 2005, 437(7057):376.

II. Meyers BC, Tej SS, Vu TH, Haudenschild CD, Agrawal V, Edberg SB, Ghazal H, Delcola S: The use of MPSS for whole-genome transcriptional analysis in Arabidopsis. Genome Res 2004, 14:164I-1653.

12. Borsani O, Zhu J, Verslues PE, Sunkar R, Zhu JK: Endogenous siRNAs derived from a pair of natural cis-antisense transcripts regulate salt tolerance in Arabidopsis. Cell 2005, I 23(7): 1279-1291.

13. Chen J, Sun M, Lee S, Zhou G, Rowley JD, Wang SM: Identifying novel transcripts and novel genes in the human genome by using novel SAGE tags. Proc Natl Acad Sci USA 2002, 99(19):12257-12262.

14. Genoscope [http://www.cns.fr/externe/English/Projets/Projet ML/ organisme ML.html]

15. Nakano M, Nobuta K, Vemaraju K, Tej SS, Skogen JW, Meyers BC: Plant MPSS databases: signature-based transcriptional resources for analyses of mRNA and small RNA. Nucleic Acids Res 2006, 34(Database issue):D73I-5.

16. Meyers BC, Lee DK, Vu TH, Tej SS, Edberg SB, Matvienko M, Tindell LD: Arabidopsis MPSS. An online resource for quantitative expression analysis. Plant Physiol 2004, 135(2):80I-8I3.

17. Coughlan SJ, Agrawal V, Meyers BC: A comparison of global gene expression measurement technologies in Arabidopsis thaliana. Comparative and Functional Genomics 2004, 5(3):245-252.

18. Cui L, Wall PK, Leebens-Mack JH, Lindsay BG, Soltis DE, Doyle IJ Soltis PS, Carlson JE, Arumuganathan K, Barakat A, Albert VA, Ma H, dePamphilis CW: Widespread genome duplications throughout the history of flowering plants. Genome Res 2006, 16(6):738-749.

19. Adams KL, Cronn R, Percifield R, Wendel JF: Genes duplicated by polyploidy show unequal contributions to the transcriptome and organ-specific reciprocal silencing. Proc Natl Acad Sci USA 2003, I00(8):4649-4654.

20. Adams KL, Wendel JF: Allele-Specific, Bidirectional Silencing of an Alcohol Dehydrogenase Gene in Different Organs of Interspecific Diploid Cotton Hybrids. Genetics 2005, I7I(4):2139-2|42. 
21. Udall JA, Swanson JM, Nettleton D, Percifield RJ, Wendel JF: A Novel Approach for Characterizing Expression Levels of Genes Duplicated by Polyploidy. Genetics 2006, I73(3): 1823-1827.

22. Tuteja JH, Clough SJ, Chan WC, Vodkin LO: Tissue-Specific Gene Silencing Mediated by a Naturally Occurring Chalcone Synthase Gene Cluster in Glycine max. Plant Cell 2004, 16(4):819-835.

23. The French-Italian Public Consortium for grapevine genome chracterization: The grapevine genome sequence suggests ancestra hexaploidization in major angiosperm phyla. In Nature Volume 449. Issue 7161 Nature Publishing Group; 2007:463.

24. Olmo HP: Grapes. In Evolution of crop plants Edited by: Simmon NW. London, Longman; 1976:294-298.

25. Soltis DE, Soltis PS, Bennett MD, Leitch IJ: Evolution of genome size in the angiosperms. Am J Bot 2003, 90(I I):1596-I603.

26. Fahey ME, Moore TF, Higgins DG: Overlapping antisense transcription in the human genome. Comparative and Functional Genomics 2002, 3(3):244-253.

27. Chen J, Sun M, Kent WJ, Huang X, Xie H, Wang W, Zhou G, Shi RZ, Rowley JD: Over $\mathbf{2 0 \%}$ of human transcripts might form senseantisense pairs. Nucleic Acids Res 2004, 32( 16):48I 2-4820.

28. Shendure J, Church G: Computational discovery of sense-antisense transcription in the human and mouse genomes. Genome Biology 2002, 3(9):research0044.

29. Rosok O, Sioud M: Systematic identification of sense-antisense transcripts in mammalian cells. Nat Biotechnol 2004, 22(I): 104

30. Yelin R, Dahary D, Sorek R, Levanon EY, Goldstein O, Shoshan A, Diber A, Biton S, Tamir Y, Khosravi R, Nemzer S, Pinner E, Walach S, Bernstein J, Savitsky K, Rotman G: Widespread occurrence of antisense transcription in the human genome. Nat Biotechnol 2003, 2 I (4):379-386.

31. Kiyosawa H, Yamanaka I, Osato N, Kondo S, Hayashizaki Y: Antisense Transcripts With FANTOM2 Clone Set and Their Implications for Gene Regulation. Genome Res 2003 , | 3(6b): | $324-1334$.

32. Riken Genome Exploration Research Group and Genome Science Group and the FANTOM Consortium, Katayama S, Tomaru Y, Kasukawa T, Waki K, Nakanishi M, Nakamura M, Nishida H, Yap CC, Suzuki M, Kawai J, Suzuki H, Carninci P, Hayashizaki Y, Wells C, Frith M, Ravasi T, Pang KC, Hallinan J, Mattick J, Hume DA, Lipovich L, Batalov S, Engstrom PG, Mizuno Y, Faghihi MA, Sandelin A, Chalk AM, Mottagui-Tabar S, Liang Z, Lenhard B, Wahlestedt C: Antisense Transcription in the Mammalian Transcriptome. Science 2005, 309(5740): I 564-I566.

33. Cheng J, Kapranov P, Drenkow J, Dike S, Brubaker S, Patel S, Long J, Stern D, Tammana H, Helt G, Sementchenko V, Piccolboni A, Bekiranov S, Bailey DK, Ganesh M, Ghosh S, Bell I, Gerhard DS, Gingeras TR: Transcriptional Maps of 10 Human Chromosomes at 5-Nucleotide Resolution. Science 2005, 308(5725): I I49-II54.

34. Meyers BC, Souret FF, Lu C, Green PJ: Sweating the small stuff: microRNA discovery in plants. Curr Opin Biotechnol 2006, I7(2): 139 .

35. UC Davis College of Agricultural and Environmental Sciences Genomics Facility [http://cgf.ucdavis.edu]
Publish with Bio Med Central and every scientist can read your work free of charge

"BioMed Central will be the most significant development for disseminating the results of biomedical research in our lifetime. "

Sir Paul Nurse, Cancer Research UK

Your research papers will be:

- available free of charge to the entire biomedical community

- peer reviewed and published immediately upon acceptance

- cited in PubMed and archived on PubMed Central

- yours - you keep the copyright

Submit your manuscript here:

http://www.biomedcentral.com/info/publishing_adv.asp
BioMedcentral 